\title{
Degradation of Nitroaromatic Pollutant by Titanium dioxide/Zinc Phthalocyanine: Study of the Influencing Factors
}

\author{
Houda Ben Yahia Smida ${ }^{1}$, Bassem Jamoussi ${ }^{2}$ \\ ${ }^{1}$ Laboratoire de Physicochimie des Matériaux, IPEST, BP51, La Marsa 2070,Tunisia \\ ${ }^{2}$ Laboratoire de Chimie Analytique \& Environnement .Institut Supérieur de l'Education et de Formation \\ Continue, Tunis, Université Virtuelle de Tunis
}

\begin{abstract}
This study suggests that Effective photocatalyst $\mathrm{ZnPc/TiO_{2 }}$ based in the association between a semiconductor titanium dioxide $\mathrm{TiO}_{2}$ and zinc phthalocyanine (ZnPc) can be applied successfully for the photocatalytic degradation of 4-Nitrophenol that has been classified as first-degree toxic pollutants. ZnPc/TiO composite was prepared. Complete degradation was achieved after irradiation with solar light. Zinc phthalocyanine and $\mathrm{ZnPc} / \mathrm{TiO}_{2}$ photocatalyst were synthesized. The effect of various parameters, such as photocatalyst loading, 4-Nitrophenol concentration, type of catalyst, $\mathrm{pH}$ of aqueous solution, type current gas and addition of $\mathrm{H}_{2} \mathrm{O}_{2}$ on photocatalytic oxidation were investigated. The degree of mineralization was tested by Total Organic Carbon experiment indicating that 4-Nitrophenol was completely mineralized. This composite $\mathrm{ZnPc} / \mathrm{TiO} \mathrm{O}_{2}$ is able to perform efficiently degradation of 4-nitrophenol using solar irradiation.
\end{abstract}

Keywords: 4-Nitrophenol, Photocatalytic degradation, Solar light, Titanium dioxide, Zinc phthalocyanine.

\section{Introduction}

Nitroaromatic compounds are recognized as environmentally hazardous. 4 - Nitrophenol (4-NP) is a nitroaromatic pollutant used for manufacturing pesticides, herbicides, explosives, dyes and pharmaceuticals (e.g. synthesis of the aspirin and acetaminophen) [1,3]. These compounds are widely distributed in the environment and have been detected in wastewater, rivers and soils [4, 6]. 4-NP can be released into soil as a result of hydrolysis of several organophosphates pesticides such as parathion and methyl parathion [7]. It is designated a major pollutant by US-Environmental Protection Agency (US-EPA) [8]. It has carcinogenic, mutagenic and toxic properties [9]. The presence of nitro group reduce electron intensity of the nitro aromatic ring thereby impeding electrophilic attack by oxygenase and oxidative degradation of 4-NP [3]. However, 4-NP is highly toxic to plants, animals and microorganisms [3]. A rapid acclimation is thus needed for the treatment process. Advanced oxidation process (AOP) could provide a solution for such environmental problem. Titanium dioxide $\left(\mathrm{TiO}_{2}\right)$ assisted photocatalysis is a well known emerging AOP for the removal of organic pollutants. $\mathrm{TiO}_{2}$ as photocatalysis shows relatively high activity but only under ultraviolet (UV) light which exceed the band-gap energy of 3.0 or $3.2 \mathrm{eV}[10,11]$ in the rutile or anatase crystalline phase, respectively. Consequently, the use of sunlight, indoor light, or other rays from artificial sources has been an appealing challenge for extending the applicability of these techniques. Attachment of dyes to the $\mathrm{TiO}_{2}$ surface is a convenient way to use solar light for sensitization of photocatalytic degradation reactions. Several attempts have been made in this direction by attaching dyes including Rose Bengal, chlorophylls, porphyrins, phthalocyanines, a ruthenium bipyridyl complex [12]. The electronic and photocatalytic properties of zinc phthalocyanine dyes have been widely studied [13].The composite prepared by association between zinc phthalocyanine $(\mathrm{ZnPc})$ [14] and $\mathrm{TiO}_{2}$ is a finely divided bluish powder with improved photocatalytic activity ${ }^{[15]}$, insoluble in water, capable to give stable suspensions in this solvent.The solar light intensity should be capable to photoexcite $\mathrm{ZnPc} / \mathrm{TiO}_{2}$ composite, generating $\mathrm{e}^{-} / \mathrm{h}^{+}$pairs in both species, and consequently favoring the electron injection from ZnPc excitons to $\mathrm{TiO}_{2}$ conduction band.In this work, $\mathrm{TiO}_{2}$ particles were coated with $\mathrm{ZnPc}$ for studies on phtocatalytic degradation of 4-NP, with solar light. Thus the prime objective of the present work was to improve the efficiency of photocatalytic process using photosensitizers $\mathrm{ZnPc} / \mathrm{TiO}_{2}$.

\subsection{Materials and methods}

\section{Experimental}

Titanium dioxide, P25, was kindly provided by Degussa Chemicals (Hanau, Germany). 4-Nitrophenol (purity 99\%) (GR, Merck, Germany) (Molecular formula $\mathrm{C}_{6} \mathrm{H}_{5} \mathrm{O}_{3} \mathrm{~N}$, molecular weight 139.11), phthalic anhydride ( $\geq 99 \%$ ), ammonium chloride ( $\geq 99.5 \%)$, urea (95\%), ammonium molybdate (99,98\%), zinc acetate ( $\geq 99 \%$ ), ethanol ( $\geq 99.5 \%$ ), nitrobenzene ( $\geq 99.0 \%$ ), methanol ( $\geq 99 \%$ ), dimethylformamide (DMF) ( $99.8 \%$ ), dimethylsulfoxide (DMSO) $(\geq 99.7 \%), \mathrm{NaOH}(\geq 98 \%), \mathrm{H}_{2} \mathrm{SO}_{4}(95.0-98.0 \%)$ were commercially purchased from Sigma-Aldrich (Germany). The $\mathrm{pH}$ of the solution was adjusted before irradiation using $\mathrm{NaOH}$ or $\mathrm{H}_{2} \mathrm{SO}_{4}$. 
The experiments under solar irradiation were performed in July 2011 from 12 to 4 p.m. The irradiation, were measured using the radiometer (PMA 2100 Solar Light Co), with the sensor positioned horizontally. The irradiation measured during the experiments varied from 15 to $20 \mathrm{~W} \mathrm{~m}^{-2}$. The intensity was nearly constant during the experiments.

\subsection{Apparatus and instruments}

UV spectral analysis was done using UV-Visible Spectrophotometer Shimadzu 1650PC. The $\mathrm{pH}$ of the solution was measured by using HANNA phep (model H 198107) digital $\mathrm{pH}$ meter. The specific surface area of the composites was estimated from BET (Brunauer, Emmett, and Teller) isotherms, based on the adsorption of gaseous nitrogen, using a MICROMERITICS ASAP 2000 system.

\subsection{Preparation of $\mathrm{ZnPc}$ and $\mathrm{ZnPc} / \mathrm{TiO}_{2}$ composite}

Phthalic anhydride $(4.32 \mathrm{~g}, 16 \mathrm{mmol})$ ammonium chloride $(0.47 \mathrm{~g}, 9 \mathrm{mmol})$, urea $(5.8 \mathrm{~g}, 97 \mathrm{mmol})$, ammonium molybdate $(0.34 \mathrm{~g}, 0.03 \mathrm{mmol})$ and zinc acetate were thoroughly mixed. The mixture was added slowly to heated $\left(180^{\circ} \mathrm{C}\right)$ nitrobenzene $(10 \mathrm{~mL})$. The mixture was heated for 6 hours at $180^{\circ} \mathrm{C}$. The crude product obtained was a dark solid cake. The product was treated in a Soxhlet extraction apparatus with methanol for 24 hours. Finally, the product was heated under reflux in $20 \mathrm{~mL}$ ethanol for 4 hours. Thereafter, cooled, filtered and dried in oven at $120^{\circ} \mathrm{C}$ for 12 hours.

According to the litterature [14], the composite was prepared coating $\mathrm{TiO}_{2}$ particles with $\mathrm{ZnPc}$. The necessary amount of $\mathrm{TiO}_{2}$ (P25 Degussa) was gradually added in a mixture of $100 \mathrm{~mL}$ (50\% DMSO, 20\% ethanol, and 30\% DMF) of a solution of $\mathrm{ZnPc}(2 \mathrm{M})$ ), stirring and heating, resulting in a suspension with a homogeneous appearance. After evaporation, the composite is dried at a temperature between 70 and $80^{\circ} \mathrm{C}$, for 24 hours. Then, the composite is reduced to a powder finitely divisible that will get stable in water suspensions.

\subsection{Characterization}

The UV-vis absorption spectrum of $\mathrm{ZnPc}$ is shown in Fig. 1. The ZnPc spectrum in DMF is similar to that of the literature [15] with two groups of absorption at 600- $700 \mathrm{~nm}$ (Q band) and at $336 \mathrm{~nm}$ (Soret band or B band).

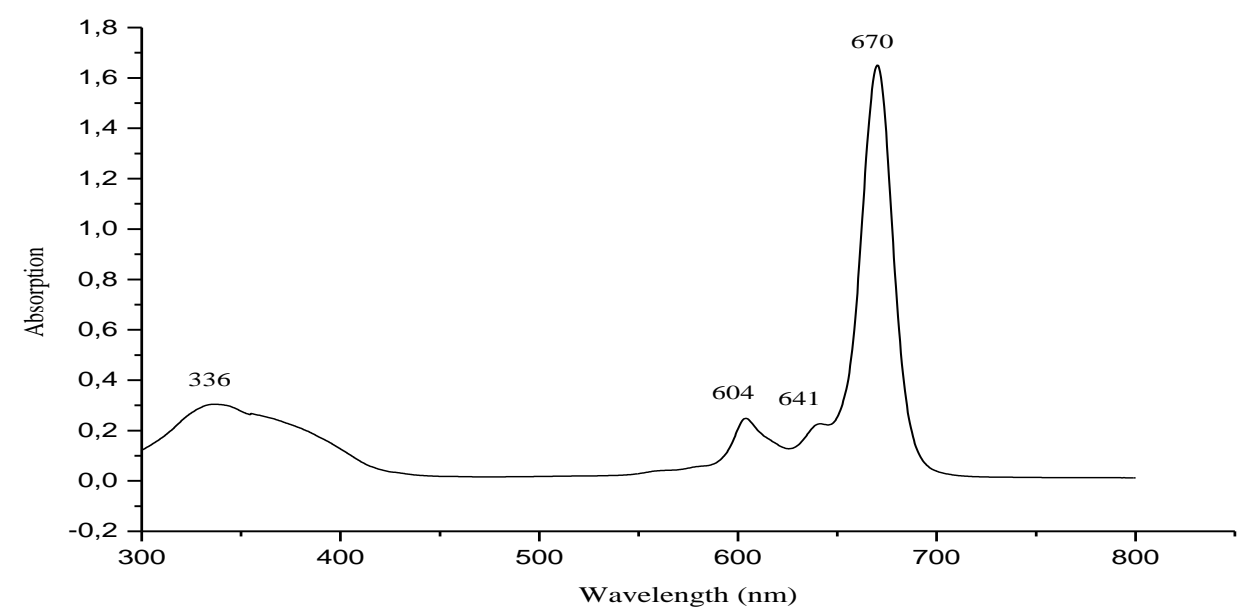

Fig. 1. UV-Vis spectrum of $\mathrm{ZnPc}$ in $\mathrm{DMF}$ solution at room temperature.

Table 1 shows the specific surface area (SSA) of pure $\mathrm{TiO}_{2}$ and of $\mathrm{ZnPc} / \mathrm{TiO}_{2}$. For pure $\mathrm{TiO}_{2}$ and composite, the peak positions and lattice parameters of the anatase and rutile phases (not shown).

Table 1: Specific surface area values for $\mathrm{TiO}_{2}$ and $\mathrm{ZnPc} / \mathrm{TiO}_{2}$ composite.

\begin{tabular}{|l|l|}
\hline Composition & $\mathrm{SSA}\left(\mathrm{m}^{2} \mathrm{~g}^{-1}\right)$ \\
\hline $\mathrm{TiO}_{2}$ & 52 \\
\hline $\mathrm{TiO}_{2} / \mathrm{PcZn}$ & 35 \\
\hline
\end{tabular}

$\mathrm{X}$-ray powder diffraction patterns of $\mathrm{TiO}_{2}$ and the $\mathrm{ZnPc} / \mathrm{TiO}_{2}$ composite only show peaks due to the anatase and rutile phases (figure not shown) [16]. 


\subsection{Procedure}

A recirculating photocatalytic reactor was constructed as shown in Fig. 2. The reaction vessel consists of a small cylinder constructed of Pyrex glass. It is connected to a reactor of $25 \mathrm{~cm}$ length and $5 \mathrm{~cm}$ diameter glass cylinder. A pump (Masterflex, Cole Parmer, USA) was used to circulate the solution. Under solar light irradiation, $\mathrm{ZnPc} / \mathrm{TiO}_{2}$ composite $(1 \mathrm{~g})$ was added in 4-NP solution $\left(1 \times 10^{-4} \mathrm{M}, 50 \mathrm{~mL}\right)$, was circulated continuously under $\mathrm{O}_{2}$ (flow rate $300 \mathrm{~mL} \mathrm{~min}{ }^{-1}$ ). At certain time intervals, small aliquots $(2 \mathrm{~mL}$ ) were withdrawn and filtered $(0.45 \mu \mathrm{m}$ Millipore filter) to remove the catalyst particles. All photocatalytic experiments were carried out at $\mathrm{pH}$ 6. The concentration of 4-NP in each degraded sample was determined with UV-Visible Spectrophotometer Shimadzu $1650 \mathrm{PC}$ at $\lambda_{\max }=316 \mathrm{~nm}$. A calibration plot based on Beer-Lamberts law was established by relating the absorbance to the concentration. Degradation rate was calculated using the following equation 1

Degradation rate $(\%)=\left\{\left(\mathrm{C}_{0}-\mathrm{Ct}\right) \div \mathrm{C}_{0}\right\} \times 100 \quad$ (1)

Where $C_{0}$ is the initial concentration of 4-NP and $\mathrm{Ct}$ is the instant concentration in the sample at time $t$.

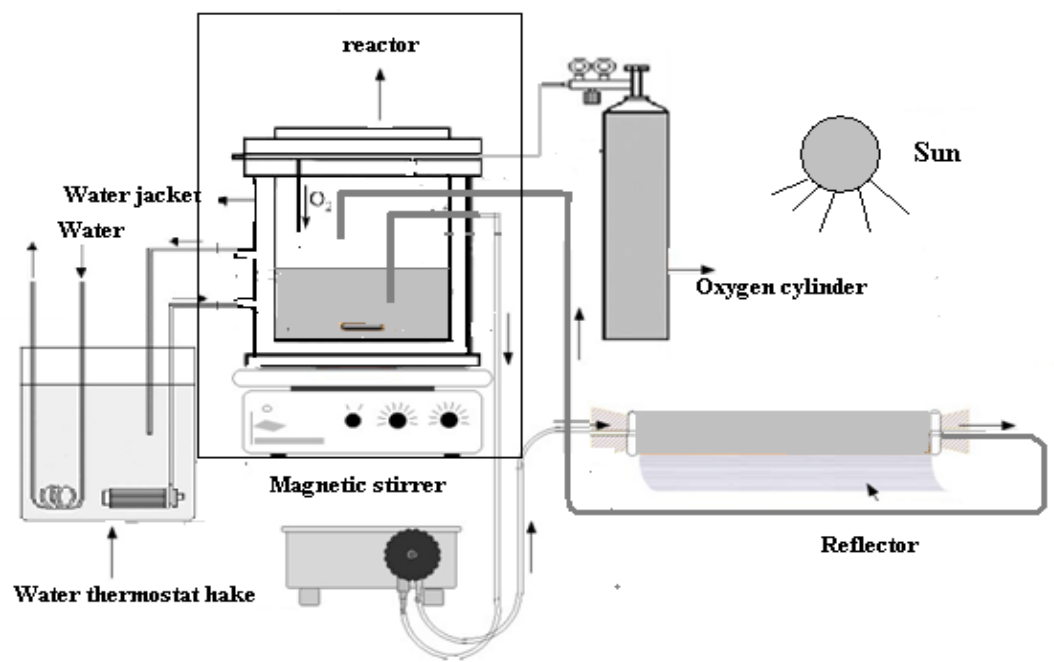

Fig. 2. Schematic diagram of the solar photocatalytic reactor system.

\subsection{Total Organic Carbon Analysis.}

The oxidative mineralization was therefore examined by measuring the Total Organic Carbon (TOC) in the solution [17]. The TOC measurements were made using Analytik jena TOC multi N/C 3100 analyzer by direct injection of the aqueous solution after centrifugation.

\subsection{Photodegradability}

\section{Result And Discussion}

The results of photodegradation with and without $\mathrm{ZnPc} / \mathrm{TiO}_{2}$ are shown in Fig. 3. The 4-NP is not degradable with solar light in the absence of catalyst $\mathrm{ZnPc} / \mathrm{TiO}_{2}$ and by $\mathrm{ZnPc} / \mathrm{TiO}_{2}$ in dark. The $9 \%$ decrease in 4-NP concentration with $\mathrm{ZnPc} / \mathrm{TiO}_{2}$ in dark is due to the adsorption of 4-NP; about $99 \%$ of 4-NP is removed after $80 \mathrm{~min}$ of solar irradiation. This reveals that the 4-NP can be degraded only in the presence of $\mathrm{ZnPc} / \mathrm{TiO}_{2}$ and solar light.

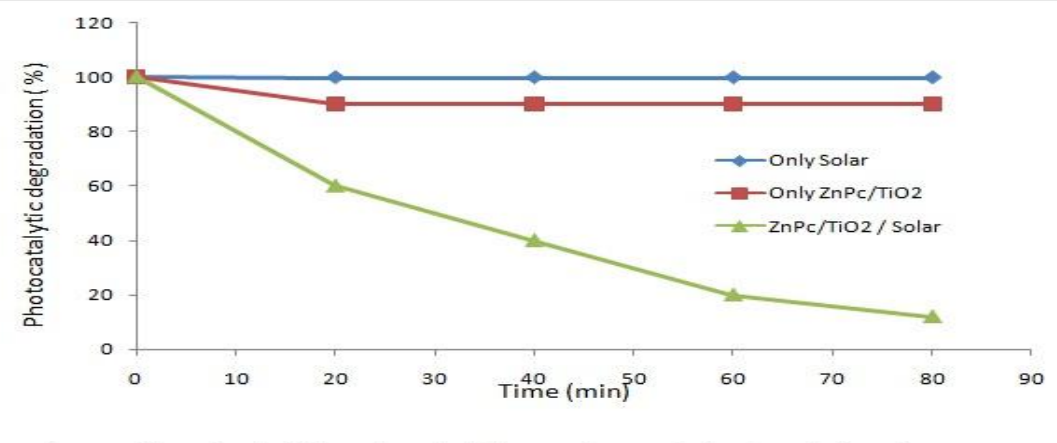

Fig. 3. Effect of solar light and $\mathrm{Zn} / \mathrm{Pc} / \mathrm{TiO}_{2}$ on photocatalytic degradation of 4-NP $[4-\mathrm{NP}]=1 \times 10^{-4} \mathrm{M} ; \mathrm{pH} 6.0 \pm 0.1$ 


\subsection{Effect of $\mathrm{pH}$ of the solution}

The effect of $\mathrm{pH}$ on the photocatalytic degradation efficiency of AOP, according to some literatures [18], is one of the major factors influencing the rate of degradation of some organic compounds. The degree of photocatlytic degradation of 4-NP was found to be affected by a change in $\mathrm{pH}$. Fig. 4 shows the effect of varying the $\mathrm{pH}$ from 2 to 12 on the degradation of 4-NP in the presence of $\mathrm{ZnPc} / \mathrm{TiO}_{2}$ under solar light irradiation. Increase of $\mathrm{pH}$ of 4-NP solution from 2 to 6 increases the degradation from $70.6 \%$ to $87 \%$ at 60 min. Degradation of 4-NP was high between $\mathrm{pH} 2$ and $\mathrm{pH} \mathrm{6}$, while the degradation efficiency was lower in the alkaline environment above $7 \mathrm{pH}$. Titania surface will remain positively charged in acidic medium $(\mathrm{pH}<7)$ and negatively charged in alkaline medium $(\mathrm{pH}>7)$. This behavior can be explained when the $\mathrm{pH}$ value of the solution is increased up to a maximum value and then decreased, this is because in alkaline medium the surface area of photocatalyst possesses much negative charge [19, 20].

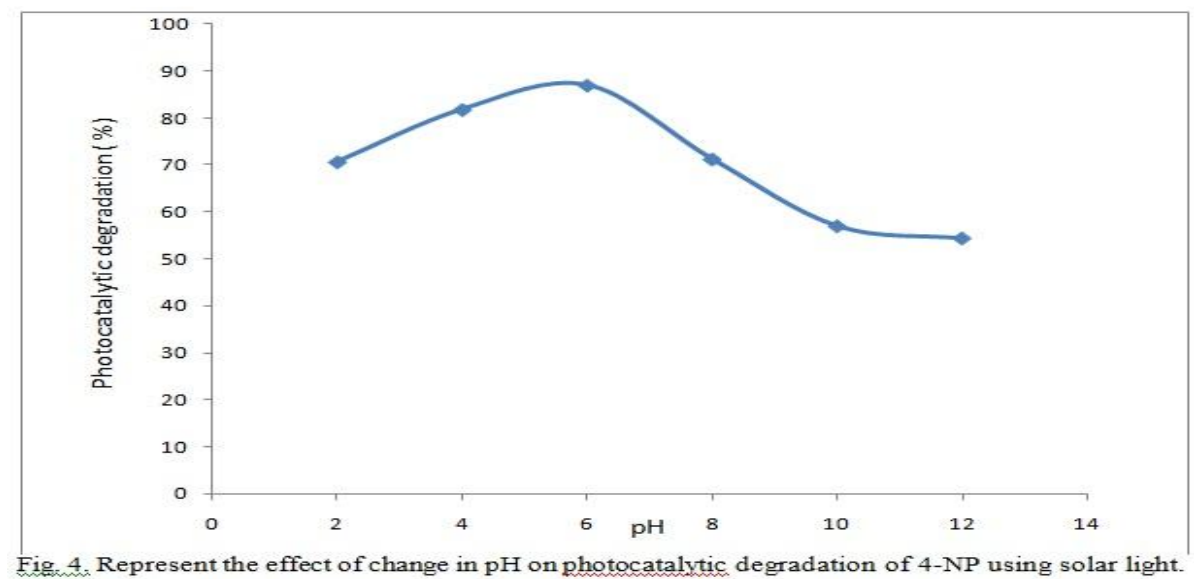

\subsection{Effect of catalyst loading}

The amount of catalyst is one of the main parameter for the degradation studies. The experiment was carried out by varying the catalyst loading from $25 \mathrm{mg} / 100 \mathrm{~mL}$ to $150 \mathrm{mg} / 100 \mathrm{~mL}$. The results are shown in Fig. 5. The percentage degradation increases rapidly from $55 \%$ to $87 \%$ with the increase in the amount of $\mathrm{ZnPc} /$ $\mathrm{TiO}_{2}$ from 25 to $100 \mathrm{mg} / 100 \mathrm{~mL}$ at $60 \mathrm{~min}$. This is due to an increase in the number of $\mathrm{ZnPc} / \mathrm{TiO}_{2}$ particles, which increases the absorption of photons and adsorption of pollutant molecules. Further increase of $\mathrm{ZnPc}^{\mathrm{TiO}} \mathrm{Ti}_{2}$ loading from 100 to $150 \mathrm{mg} / 100 \mathrm{~mL}$, decreases the removal rate. At high solute concentration availability of excess active sites outweighs the diminishing photoactivated volume and significantly greater percentage is achieved at increased $\mathrm{ZnPc} / \mathrm{TiO}_{2}$ loading. Thus, the decreased percentage degradation at higher catalyst loading may be due to deactivation of activated molecules by collision with ground state molecules. Hence, an optimum catalyst has to be added in order to avoid unnecessary excess catalyst and also to ensure total absorption of solar light photons [21] for efficient photomineralisation. The optimum amount of catalyst loading was found to be $100 \mathrm{mg} / 100 \mathrm{~mL}$ of the degradation of 4-NP. Hence, $100 \mathrm{mg} / 100 \mathrm{~mL}$ was used as the catalyst dosage for the photocatalytic reaction.

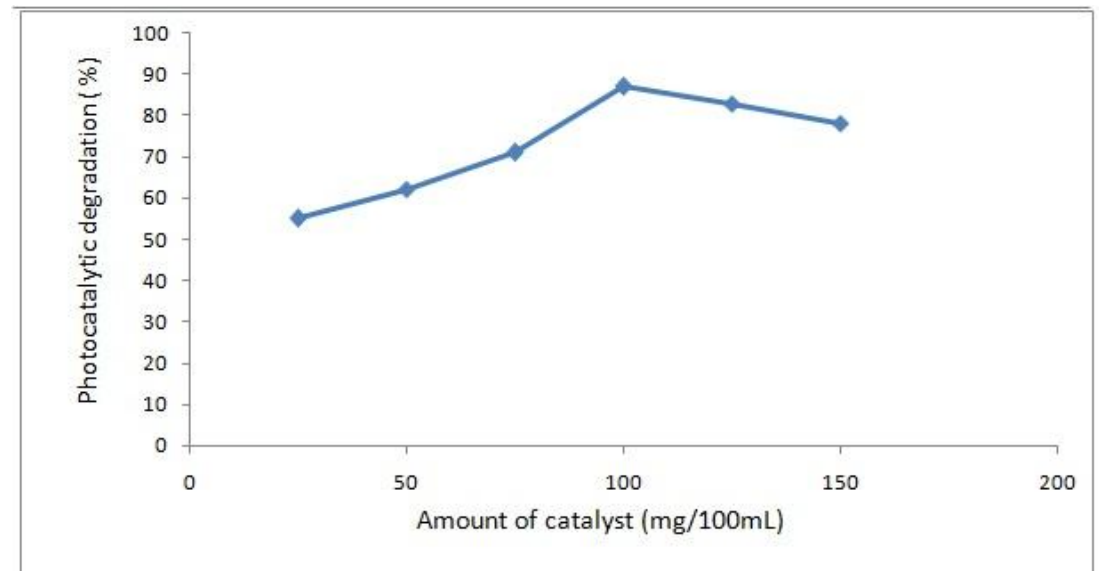

Fig. 5. Effect of catalyst weight on the degradation of 4-NP using solar light; [4-NP] $=1 \times 10^{-4} \mathrm{M} ; \mathrm{pH}$ $6.0 \pm 0.1$; irradiation time $=60 \mathrm{~min}$. 
Degradation of Nitroaromatic Pollutant by Titanium dioxide/Zinc Phthalocyanine: Study of the

\subsection{Effect of 4- NP concentration}

The effect of initial concentration of 4-NP on the percentage degradation was studied by varying the initial concentration from $1 \times 10^{-4}$ to $6 \times 10^{-4} \mathrm{M}$ with optimum catalyst loading. The results are shown in Table 2. Increase in the concentration of 4-NP decreases the degradation of 4-NP from $98.81 \%$ to $20.37 \%$ in $60 \mathrm{~min}$ of irradiation time. The possible explanation for this behavior is that as the initial concentration of the 4-NP increases, the path length of photons entering the solution decreases and in low concentration the reverse effect is observed, thereby increasing the number of photon absorption by the catalyst in lower concentration [22]. The pollutant molecule rather than the catalyst may absorb a significant amount of solar light and this may also reduce the catalytic efficiency.

Table 2: Effect of initial concentration of 4-NP on the photocatalytic degradation of 4-NP using Solar light $\mathrm{ZnPc} / \mathrm{TiO}_{2}=100 \mathrm{mg} / 100 \mathrm{~mL} ; \mathrm{pH} 6.0 \pm 0.1$.

\begin{tabular}{|l|l|}
\hline Concentration of 4-NP $\left(10^{-4} \mathrm{M}\right)$ & Degradation $(\%)$ \\
\hline 1 & 98.81 \\
2 & 72.19 \\
3 & 57.24 \\
4 & 46.12 \\
5 & 35.64 \\
6 & 20.37 \\
\hline
\end{tabular}

\subsection{Effect of Current Gas}

The results in fig. 6 shows that the photodegradation efficiency for 4-NP increased with the presence the oxygen gas $\left(\mathrm{O}_{2}\right)$ but the decreases or was extremely slow in the presence the nitrogen gas $\left(\mathrm{N}_{2}\right)$. This behavior can be explained that in the presence of nitrogen gas $\left(\mathrm{N}_{2}\right)$ and $\mathrm{ZnPc} / \mathrm{TiO}_{2}$ will production grey-blue in color may be attributed to the sharing of lattice oxygen from the surface. The results indicated that the presence of oxygen necessary $[23,24]$. The presence of oxygen in the solution plays an important role in the photocatalytic degradation of 4-NP. This behavior can be explained that the oxygen molecule acts as an electron acceptor and minimizes the chance of electron-hole pair recombination [25].

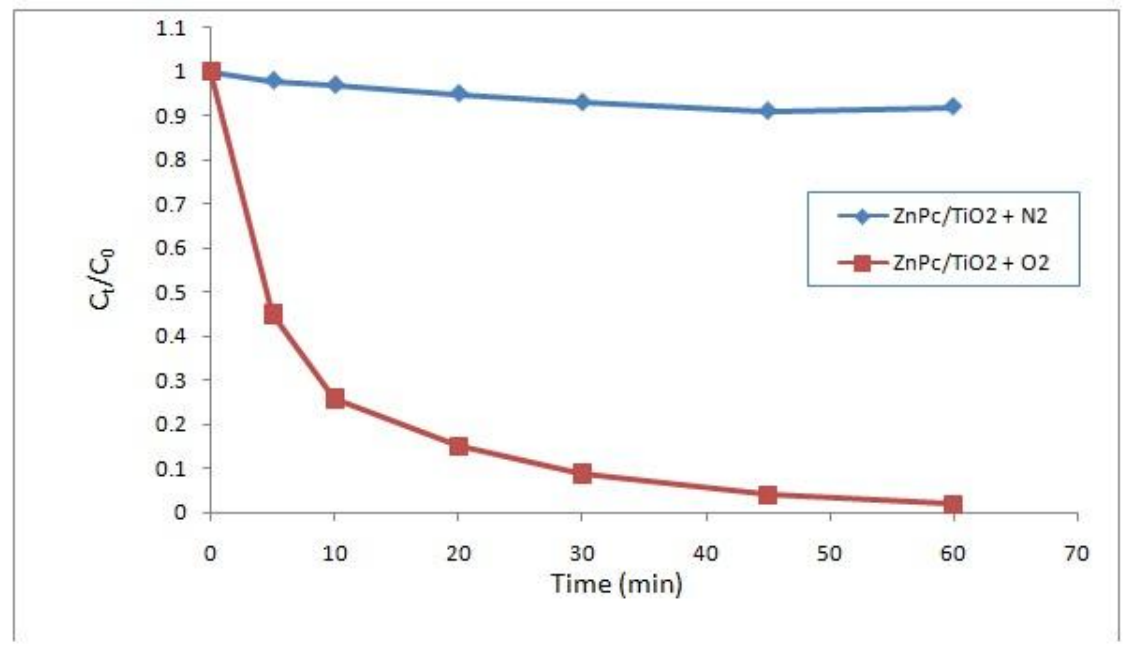

Fig. 6. Effect of type of gas on the degradation of 4-NP using solar light $\mathrm{ZnPc} / \mathrm{TiO}_{2}=100 \mathrm{mg} / 100$ $\mathrm{mL} ;[4-\mathrm{NP}]=1 \times 10^{-4} \mathrm{M} ; \mathrm{pH} 6.0 \pm 0.1$; irradiation time $=60 \mathrm{~min}$.

\subsection{Effect of addition of $\mathrm{H}_{2} \mathrm{O}_{2}$}

The photocatalytic degradation of organic pollutants depends upon their reactions with the hydroxyl radicals ${ }^{\circ} \mathrm{OH}$. Therefore, electron acceptors have been used to enhance the degradation rates since they generate 'OH radicals [26]. Hydrogen peroxide $\left(\mathrm{H}_{2} \mathrm{O}_{2}\right)$ plays an important role in the production of hydroxyl radicals. The effect of addition of hydrogen peroxide $\mathrm{H}_{2} \mathrm{O}_{2}$ on the degradation was studied for photocatalytic oxidation of the 4-NP. The results in fig. 7 show that the degradation increases from 82.1 to $87 \%$ with increases concentration of hydrogen peroxide $\mathrm{H}_{2} \mathrm{O}_{2}$ from 4 to $16 \mathrm{mmol}$ at $60 \mathrm{~min}$. This behavior is due to the increasing the concentration of hydroxyl radical since it inhibits the hole-electron recombination according to the following equation 2.

$\mathrm{H}_{2} \mathrm{O}_{2}+\mathrm{e}^{-}{ }_{\mathrm{cb}} \longrightarrow{ }^{\circ} \mathrm{OH}+\mathrm{OH}^{-} \quad$ equation (2) 


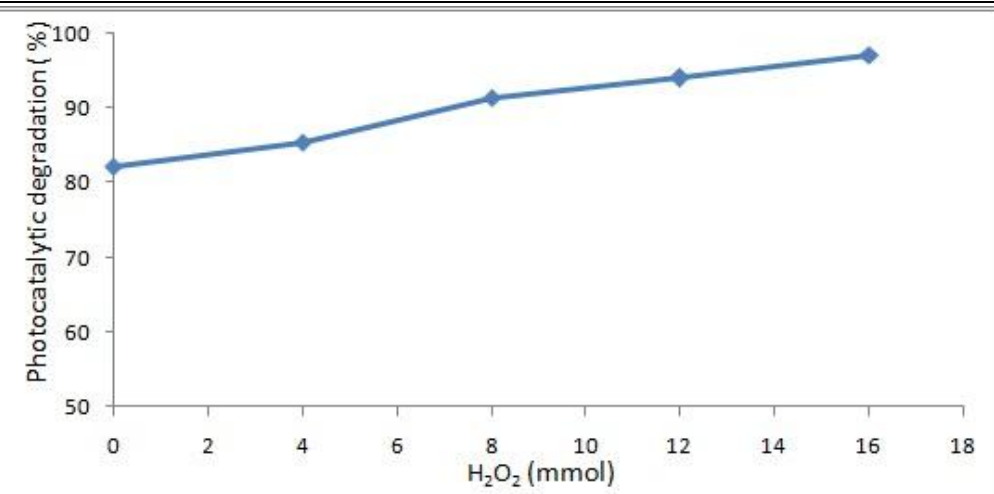

Fig. 7. Effect of addition of $\mathrm{H}_{2} \mathrm{O}_{2}$ concentration on the degradation of 4-NP using solar light $\mathrm{ZnPc} /$ $\mathrm{TiO}_{2}=100 \mathrm{mg} / 100 \mathrm{ml} ;[4-\mathrm{NP}]=1 \times 10^{-4} \mathrm{M} ; \mathrm{pH} 6.0 \pm 0.1$; irradiation time $=60 \mathrm{~min}$.

\subsection{Total Organic Carbon (TOC) Analysis.}

Fig. 8 show the results of the TOC experiment indicating that 4-NP was mineralized up to $87.7 \%$ within the period of $80 \mathrm{~min}$. This indicates mineralization of 4-NP. Mineralization of 4-NP was also revealed by the formation of carbon dioxide during photodegradation. Carbon dioxide formation was tested by passing the evolved gas during photodegradation into lime water.

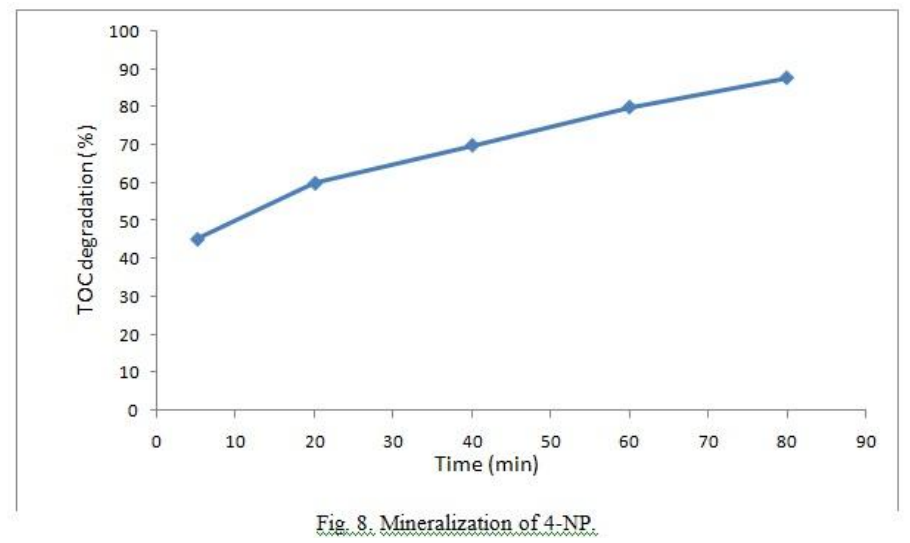

\section{Conclusion}

In this study, Zinc phthalocyanine-modified titanium dioxide, $\mathrm{ZnPc} / \mathrm{TiO} 2$, as photocatalyst was synthesized. $\mathrm{ZnPc} / \mathrm{TiO}_{2}$ has been found to be most active catalyst, exhibiting high photocatalytic activity. 4-NP is successfully degraded by $\mathrm{ZnPc} / \mathrm{TiO}_{2}$ assisted photocatalysis in aqueous dispersion under irradiation by Solar light. Photocatalytic degradation of 4-NP depends on the amount of catalyst, initial concentration, $\mathrm{pH}$. The optimum concentration of oxidant $\mathrm{H}_{2} \mathrm{O}_{2}$, for enhanced degradation is 8 mmol. Photocatalytic mineralization of 4-NP (97\%) was achieved using $\mathrm{ZnPc} / \mathrm{TiO}_{2}$, after a period of $80 \mathrm{~min}$. The solar assisted photocatalysis with $\mathrm{ZnPc} / \mathrm{TiO}_{2}$ can be used as a viable technique for the treatment of 4-NP (an organic pollutant).

\section{References}

[1] M. Kulkarni and A. Chaudhari, Microbial remediation of nitro-aromatic compounds: An overview, Journal of Environmental Management, 85, 2007, 496-512.

[2] J. C. Spain and D. T. Gibson D, Pathway for biodegradation of pnitrophenol in a Moraxella species, Applied and Environmental Microbiology, 57, 1991, 812-819.

[3] C. Bruhn, H. Lenke, and H. J. Kanckmuss, Nitrosubstituted aromatic compounds as nitrogen source for bacteria, Applied and Environmental Microbiology, 53, 1987, 208- 210.

[4] F. D. Marvin-Sikkema, and J. A. M. de Bont, Degradation of nitroaromatic compounds by Microorganisms, Applied and Environmental Biotechnology, 42, 1994, 499-507.

[5] S. F. Nisbino, and J. C. Spain, Cell density-dependent adaptation of Pseudomon as putida to biodegradation of p-nitrophenol, Environmental Science Technology, 27, 1993, 489- 494.

[6] M. A. Oturan, J. Peiroten, P. Chartrin, and A. J. Acher, Complete destruction of p-nitrophenol in aqueous medium by electroFenton method, Environmental Science Technology, 34, 2000, 3474- 3479.

[7] G. R. Chaudhry, A. N. Ali, and W. B. Wheeler, Isolation of a methyl parathion-degrading Pseudomonas sp that possesses DNA homologous to the opd gene from a Flavobacterium sp, Applied and Environmental Microbiology, 54(2), 1988, 288- 293.

[8] D. Errampalli, O. Tresse, H. Lee, and J. T. Trevors, Bacterial survival and mineralization of p-nitrophenol in soil by green fluorescent protein-marked Moraxella sp. G21 encapsulated cells, FEMS Microbiology Ecology, 30, 1999, 229- 236. 
[9] G. E. Parris, Environmental and metabolic transformation of primary aromatic amines and related compounds, Residue Revue, 76, 1980, 1- 30 .

[10] G. Palmisano, V. Augugliaro, M. Pagliaro, and L. Palmisano, Photocatalysis: a promising route for $21 \mathrm{st}$ century organic chemistry, Chemical Communications, 33, 2007, 3425-3437.

[11] Hoffmann M.R., Martin S. T., Choi W. and D. W. Bahnemann, Environmental applications of semiconductor photocatalysis, Chemical Reviews, 1, 1995, 69- 69.

[12] L. Guangming, A. Klein, A. Thissen, and W. Jaegermann, Electronic properties and interface characterization of phthalocyanine and Ru-polypyridine dyes on $\mathrm{TiO}_{2}$ surface, Surface Science, 539, 2003, 37- 48.

[13] F. Evangelista, V. Carravetta, G. Stefani, B. Jansik, M. Alagia, S. Stranges, and A. Ruocc, Electronic structure of copper phthalocyanine: An experimental and theoretical study of occupied and unoccupied levels, Journal of Chemical Physics, 126 (12), 2007, 124709/1-124709/10.

[14] A. E. H. Machado, J. A. Miranda, C. Sattler, and L. Oliveira, Zinc phthalocyanine and titanium oxide composites used as, e.g. catalyst for wastewater decontamination, prepared by combining titanium oxide and photosensitizer dye capable of potentializing photocatalytical action of titanium oxide, (European patent no. EP1646443-A2, 2006).

[15] A. W. Snow, and N. L. Jarvis, Molecular association and monolayer formation of soluble phthalocyanine compounds Journal of the American Chemical Society, 106, 1984, 4706- 4711.

[16] X. H. Qiu, G. V. Nazin, and W. Ho, Mechanisms of reversible conformational transitions in a single molecule, Physical Review Letters, 93 (19), 2004, 196806.

[17] D. Behar, P. Neta, and C. Schultheisz, Reaction Kinetics in Ionic Liquids as Studied by Pulse Radiolysis: Redox Reactions in the Solvents Methyltributylammonium Bis (tri-fluoromethylsulfonyl)imide and N-Butylpyridinium Tetrafluoroborate, Journal of Physical Chemistry A, 105 (32), 2001, 7607-7614.

[18] K. H. Wang, Y. H. Hisieh, C. H. Wu, and C. Y. Chang, The pH and anion effects on the heterogeneous photocatalytic degradation of o-methylbenzoic acid in $\mathrm{TiO}_{2}$ aqueous suspension, Chemosphere, 40, 2000, 389-394.

[19] Y. Wang, Solar photocatalytic degradation of eight commercial dyes in $\mathrm{TiO}_{2}$ suspension, Water Research, 34, $2000,990-994$.

[20] Y. C. Chung, and Y. C. Chen, Degradation of azo dye reactive violet 5 by $\mathrm{TiO}_{2}$ photocatalysis, Environmental Chemistry Letters, 7, 2009, 347- 352.

[21] J. M. Herrmann , Heterogeneous Photocatalysis: an Emerging Discipline Involving Multiphase Systems, Catal Today, 24 (1), 1995, 157- 164 .

[22] R. J. Davis, J. L. Gainer, G. O. Neal, and I. Wenwu, Photocatalytic decolourisation of wastewater dyes, Water Environment Research, 66, 1994, 50- 53.

[23] V. Mirkhani, S. Tangestaninejad, M. Moghadam, M. H. Habibi, and A. Rostami-Vartooni, Photocatalytic degradation of azo dyes catalyzed by Ag doped TiO2 photocatalyst Journal of The Iranian Chemical Society, 6 (3), 2009, $578-587$.

[24] R. Zhang, C. Zhang, X. X. Cheng, L. Wang, Y. Wu, and Z. Guana, Kinetics of decolorization of azo dye by bipolar pulsed barrier discharge in a three-phase discharge plasma reactor, Journal of Hazardous Materials, 142, 2007, $105-110$.

[25] Litter M. I., Heterogeneous photocatalysis transition metal ions in photocatalytic systems, Applied Catalysis B: Environmental, 23, 1999, 89- 114.

[26] L. Sun and J. R. Bolton, Determination of the quantum yield for the photochemical generation of hydroxyl radicals in TiO 2 suspensions, Journal of Physical Chemistry, 100(10), 1996, 4127- 4134. 